\title{
(2) OPEN ACCESS \\ Sex-specific and age-specific suicide mortality by method in 58 countries between 2000 and 2015
}

\author{
Yue Wu, ${ }^{1}$ David C Schwebel $(1),{ }^{2}$ Yun Huang, ${ }^{1}$ Peishan Ning, ${ }^{3}$ Peixia Cheng, ${ }^{3}$ \\ Guoging $\mathrm{Hu}$ (1) $^{3}$
}

- Additional material is published online only. To view please visit the journal online (http://dx.doi.org/10.1136/ injuryprev-2019-043601).

${ }^{1}$ Department of Occupational and Environmental Health, Xiangya School of Public Health, Central South University, Changsha, China

2Department of Psychology, University of Alabama at Birmingham, Birmingham, Alabama, USA

${ }^{3}$ Department of Epidemiology and Health Statistics, Xiangya School of Public Health, Central South University, Changsha, Hunan, China

\section{Correspondence to}

Dr Guoqing Hu, Department of Epidemiology and Health Statistics, Xiangya School of Public Health, Central South University, Changsha, China; huguoqing009@gmail.com

Received 3 December 2019 Revised 6 January 2020 Accepted 7 January 2020 Published Online First 8 March 2020

\section{ABSTRACT \\ Objective To examine recent changes in sex-specific and age-specific suicide mortality by method across countries.}

Methods Using mortality data from the WHO mortality database, we compared sex-specific, age-specific and country-specific suicide mortality by method between 2000 and 2015. We considered seven major suicide methods: poisoning by pesticides, all other poisoning, firearms and explosives, hanging, jumping from height, drowning and other methods. Changes in suicide mortality were quantified using negative binomial models among three age groups (15-44 years, 45-64 years, and 65 years and above) for males and females separately.

Results Suicide mortality declined substantially for both sexes and all three age groups studied in 37 of the 58 included countries between 2000 and 2015. Males consistently had much higher suicide mortality rates than females in all 58 countries. Hanging was the most common suicide method in the majority of 58 countries. Sex-specific suicide mortality varied across 58 countries significantly for all three age groups. The spectrum of suicide method generally remained stable for 28 of 58 included countries; notable changes occurred in the other 30 countries, including especially Colombia, Finland and Trinidad and Tobago.

Conclusion Likely as a result of prevention efforts as well as sociodemographic changes, suicide mortality decreased substantially in 37 of the included 58 countries between 2000 and 2015. Further actions are needed to explore specific drivers of the recent changes (particularly for increases in eight countries), to understand substantial disparities in suicide rates across countries, and to develop interventions to reduce suicide rates globally.

\section{INTRODUCTION}

Suicide is a significant public health problem internationally and is responsible for over 793800 deaths in 2017 according to estimates from the Global Burden of Disease (GBD) study group. ${ }^{1}$ Although suicide mortality varies substantially by sex and age group and across regions and countries, ${ }^{2}$ suicide places among the top three causes of death for people aged 15-44 years in several countries. ${ }^{1}$ The United Nations lists suicide prevention as a specific target in the Sustainable Development Goals (SDGs), 'reducing by one-third premature mortality from non-communicable diseases by 2030 (including suicide)' ${ }^{3}$
In the past few decades, successful suicide prevention measures have been developed in many countries to reduce self-harm and suicide. Implemented strategies include improved access to mental health and welfare services, reduced use of alcohol and promotion of responsible media reporting about suicide. ${ }^{2}$ Perhaps the most successful suicide prevention strategy, however, is restricting access to lethal means. ${ }^{245}$ This prevention strategy has been widely promoted to prevent suicide by international organisations such as WHO and the UNICEF, individual governments, non-government organisations, as well as injury researchers in the last decade. ${ }^{6-9}$

In order to best promote efforts to prevent suicide, including by restricting access to lethal means, it is important to understand the patterns of sex-specific and age-specific suicide mortality by method across individual countries around the world. Previous research offers some indication of these patterns. One publication, for example, reported varying spectrums of suicide methods and method-specific suicide mortality across sex, age groups, and regions and countries before 2005, ${ }^{10}$ revealing hanging as the predominant method of suicide in most countries and firearms suicide in the USA. In addition, a few studies report suicide mortality patterns for specific suicide methods among certain age groups in a single nation or region. ${ }^{11-15}$ As an example, one study reported that firearm suicide mortality decreased globally from 1990 to $2016 .{ }^{11}$ Another study on suicide by charcoal burning showed that charcoal-burning suicide mortality increased significantly in some East/Southeast Asian countries/territories in the first decade of the 21 st century. ${ }^{12}$ No published study examines, however, recent changes within countries across the world in sex-specific and agespecific suicide mortality by method. Since epidemiological characteristics may change as the result of prevention efforts and socioeconomic development, this knowledge would be valuable for prevention planning by a range of stakeholders.

The WHO mortality database is a freely available data source with national-level mortality data reported by all WHO Member States from 1979 to 2016. ${ }^{16}$ The database provides detailed data on the methods used in suicide, extending beyond the two cause/method groups (self-harm by firearm and selfharm by other specified means) used in the GBD database. $^{1}$

Using the latest WHO mortality data, therefore, we compared sex-specific and age-specific suicide 
mortality by method between 2000 and 2015 in all member countries covered by the WHO mortality database.

\section{METHODS}

\section{Data source}

Suicide mortality data were extracted from the WHO mortality database, which provides detailed death registration data for about 150 countries and regions. ${ }^{16}$ To ensure we obtained the most statistically reliable data possible concerning sex-specific, age-specific and method-specific suicide mortality rates, we applied the following criteria to determine eligible countries for this study: (1) country/territory's vital registration data were assessed as medium or high quality by $\mathrm{WHO}^{17} ;(2)$ at least 8 years of data were available between 2000 and 2015 in the WHO mortality database; (3) at least 100 suicide deaths were reported for people aged 15 years and older in a single year and (4) deaths were coded using the 10th International Classification of Disease (ICD-10). In total, 58 countries or territories met the inclusion criteria.

\section{Methods of suicide}

Following the approach by Ajdacic-Gross et al, ${ }^{10}$ we classified suicide into seven categories based on the ICD-10 codes: (1) poisoning by pesticides (X68); (2) all other poisoning (X60X67, X69); (3) firearms and explosives (X72-X75), (4) hanging (X70); (5) jumping from height (X80); (6) drowning (X71); (7) other methods (X76-79, X81-84).

\section{Data analysis}

We performed interpolation and (or) extrapolation to impute the missing values from 2000 to 2015 for each country. ${ }^{17}$ Specifically, the mean death rate of the first or last 3 years was extrapolated to impute the missing values in the starting or ending years. For missing values occurring in the middle of the time series, we replaced them with the mean death rate of all available data in a 7 -year window (3 years on either side around the year with missing values). ${ }^{17}$ The following missing values were estimated using these strategies: Australia, 2005; Austria, 2000, 2001; Bulgaria, 2000-2004, 2015; Canada, 2014, 2015; Costa Rica, 2000, 2015; Cuba, 2000; France, 2015; Guatemala, 2000-2004, 2015; Guyana, 2000, 2014, 2015; Hong Kong Special Administrative Region (Hong Kong SAR), 2000; Ireland, 2000-2006, 2015, Italy, 2000-2002; Mauritius, 2000-2004, 2015; New Zealand, 2014, 2015; Panama, 2015; Philippines, 2004, 2005, 2012-2015; Portugal, 2000, 2001, 2004-2006, 2015; Slovakia, 2011, 2015; Suriname, 2015; TFYR Macedonia, 2000-2005, 2014, 2015; Trinidad and Tobago, 2012-2015; UK, 2000; Uruguay, 2011; Uzbekistan, 2000-2003, 2006-2008, 2015 and Venezuela, 2014, 2015. In addition, we used a previously published method ${ }^{18}$ to redistribute injury deaths coded as undetermined intent (ICD-10 codes: Y10-Y34).

We analysed data for persons aged $\geq 15$ years because suicide is uncommon in children and early adolescence and determining suicidal intent in younger children can be difficult. ${ }^{19}$ According to previous studies, ${ }^{20} 21$ age was divided into four groups: 15-24 years, 25-44 years, 45-64 years and 65 years and older. Following preliminary analyses, we decided to combine adolescents and young adults into one age group (15-44 years) because they showed very similar suicide method patterns and changing trends in most countries. We calculated age-adjusted mortality rates using the direct standardisation method, in which the new WHO world standard population (WHO millennium) ${ }^{22}$ was used as the reference population. A univariate negative binomial regression model was run to examine the significance of changes in mortality between 2000 and 2015, using percentage change in mortality rate and its $95 \% \mathrm{CI}$. The percentage change was calculated as '(mortality rate ratio -1$) \times 100$ ', while the mortality rate ratio was calculated by dividing the mortality rate for 2015 with the corresponding rate of $2000 .^{23}$

We first analysed the changing patterns of suicide for both sex. Then, method-specific subgroup analyses by sex and age group were conducted. Statistical analyses were completed using Stata V.12.1 (StataCorp).

\section{RESULTS}

\section{Suicide among people aged $\mathbf{1 5 - 4 4}$ years old}

Between 2000 and 2015, the total number of suicide deaths in the 58 included countries among adults aged 15-44 years decreased from 80647 to 61180 . The male to female suicide mortality ratio ranged from 2.0 in Republic of Korea to 12.3 in Puerto Rico in 2000, and from 1.7 in Uzbekistan to 8.5 in Latvia in 2015.

For males, suicide mortality decreased in 37 countries but increased in 8 countries between 2000 and 2015, with the largest decrease in South Africa $(-69 \%, 95 \%$ CI $-73 \%$ to $-65 \%)$ and the greatest increase in Ecuador (50\%, 95\% CI 31\% to 73\%) (table 1 ). Suicide mortality ranged greatly across the 58 countries in 2000 (from 4.8 to 85.9 per 100000 people in Philippines and in Lithuania, respectively) and in 2015 (from 2.2 to 73.4 per 100000 people in South Africa and in Guyana, respectively) (table 1). Between 2000 and 2015, the leading suicide method changed from other poisoning to hanging in Finland, from firearms and explosives to hanging in Columbia and South Africa, from pesticide poisoning to hanging in Trinidad and Tobago, and from hanging to pesticide poisoning in Suriname between 2000 and 2015 (figure 1, online supplementary tables S1 and S2). The most common suicide method was hanging in 54 of the 58 countries in 2015. Pesticide poisoning was most common in two countries, and firearms and explosives and jumping from a height in one country each (figure 1, online supplementary table S2).

For females, suicide mortality experienced a decrease in 19 countries (greatest in South Africa: $-65 \%$, 95\% CI $-73 \%$ to $-55 \%$ ) but an increase in eight countries (greatest in Mexico: 98\%, 95\% CI 76\% to 122\%) between 2000 and 2015 (table 1). Female suicide mortality rates also varied substantially across the 58 countries, with a 12-fold gap in 2000 (20.0 per 100000 people in Guyana and 1.6 per 100000 people in Mexico) and a 40-fold gap in 2015 (24.4 per 100000 people in Guyana and 0.6 per 100000 people in South Africa) (table 1). Between 2000 and 2015, the leading suicide method transferred from other poisoning to hanging in seven countries (New Zealand, France, Sweden, Puerto Rico, UK, Colombia, TFYR Macedonia), and from hanging to other poisoning in Germany and Mauritius (figure 1, online supplementary tables S1 and S2). In 2015, hanging, other poisoning, pesticide poisoning and jumping from a height were the most prevalent suicide methods in 47, 5, 3 and 3 countries for females, respectively (figure 1, online supplementary table S2).

\section{Suicide among people aged $45-64$ years old}

Among adults aged 45-64 years, the total number of suicide deaths across the 58 countries rose from 57497 in 2000 to 67777 in 2015 . The male to female suicide mortality ratio ranged from 1.6 in Netherlands to 10.1 in Puerto Rico in 2000, and from 2.0 in Hong Kong SAR to 9.4 in Guatemala in 2015. 
Table 1 Age-standardised mortality (/100 000 persons) and per cent change in mortality between 2000 and 2015 among persons aged 15-44 years

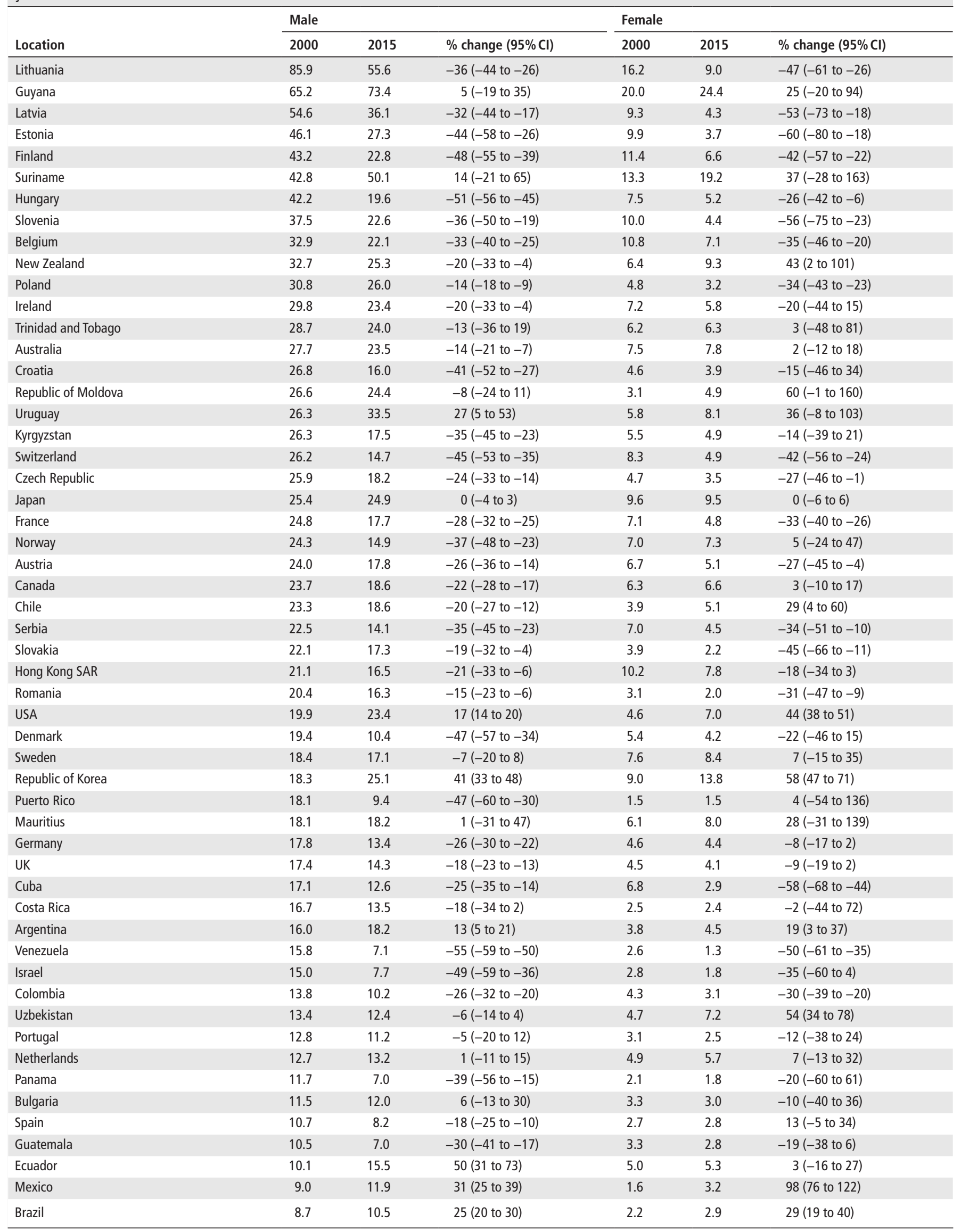


Table 1 Continued

\begin{tabular}{|c|c|c|c|c|c|c|}
\hline \multirow[b]{2}{*}{ Location } & \multicolumn{3}{|l|}{ Male } & \multicolumn{3}{|c|}{ Female } \\
\hline & 2000 & 2015 & $\%$ change $(95 \% \mathrm{Cl})$ & 2000 & 2015 & $\%$ change $(95 \% \mathrm{Cl})$ \\
\hline Italy & 8.5 & 7.6 & $-10(-18$ to -2$)$ & 2.3 & 1.9 & -15 ( -29 to 1$)$ \\
\hline TFYR Macedonia & 8.2 & 8.9 & 13 (-27 to 74$)$ & 2.5 & 2.9 & 11 (-49 to 144$)$ \\
\hline South Africa & 7.3 & 2.2 & $-69(-73$ to -65$)$ & 1.8 & 0.6 & $-65(-73$ to -55$)$ \\
\hline Philippines & 4.8 & 5.7 & 19 (10 to 30$)$ & 1.8 & 1.9 & $9(-5$ to 25$)$ \\
\hline
\end{tabular}

Mortality rates were age adjusted using the new WHO world standard population (WHO millennium).

For males, suicide mortality decreased in 27 countries (greatest decrease in South Africa: $-76 \%, 95 \%$ CI $-82 \%$ to $-68 \%$ ) but rose in 9 countries (greatest increase in Republic of Korea: 57\%, 95\% CI 48\% to 66\%) between 2000 and 2015 (table 2). A 30-fold and 55 -fold mortality gap, respectively, occurred in 2000 (5.3 per 100000 people in Philippines and 162.3 per 100000 people in Lithuania) and in 2015 (1.6 per 100000 people in South Africa and 88.1 per 100000 people in Lithuania) (table 2). Hanging was the leading suicide method in 46 of the 58 countries in 2000 and in 53 of the 58 in 2015. Between 2000 and 2015, the most prevalent suicide method changed from other poisoning to hanging in New Zealand and Australia, from firearms and explosives to hanging in Switzerland and Columbia, from pesticide poisoning to hanging in Costa Rica, from other methods to hanging in Guatemala, and from pesticide poisoning to other poisoning in Trinidad and Tobago (figure 2, online supplementary tables S3 and S4). The most prevalent suicide method was hanging in 53 countries, pesticide poisoning in 2 countries, and other poisoning, firearms and explosives and jumping from a height in 1 country each in 2015 (figure 2, online supplementary table S4).

For females, suicide mortality decreased in 18 countries (largest in Kyrgyzstan: $-61 \%$, 95\% CI $-79 \%$ to $-28 \%$ ) but increased in 6 countries (greatest in Australia: 69\%, 95\% CI 36\% to 110\%) between 2000 and 2015 (table 2). Female suicide mortality ranged dramatically across the 58 countries both in $2000(0.8$ per 100000 people for South Africa to 28.5 per 100000 people for Lithuania) and in 2015 (0.5 per 100000 people for South Africa to 18.0 per 100000 people for Belgium) (table 2). Between 2000 and 2015, the most prevalent suicide method changed from other poisoning to hanging in France, Colombia and UK; from firearms and explosives to hanging in Uruguay; from jumping from a height to hanging in Israel and Italy; from pesticide poisoning to hanging in Republic of Korea and Panama; from hanging to other poisoning in Hungary, Austria and Germany; and from pesticide poisoning to other poisoning in Trinidad and Tobago (figure 2, online supplementary tables S3 and S4). In 2015, the most prevalent suicide method was hanging in 40 countries, other poisoning in 14 countries, pesticide poisoning in 2 countries and jumping from a height in 1 country (figure 2 , online supplementary table S4).

\section{Suicide among people aged 65 years and above}

Among people aged 65 years and above, the total number of suicide deaths across the 58 countries increased from 37170 in 2000 to 44019 in 2015 . The male to female suicide mortality ratio ranged from 1.5 per 100000 people in Suriname to 17.3 per 100000 people in Colombia in 2000, and from 1.9 per 100000 people in Hong Kong SAR to 32.2 per 100000 people in Puerto Rico in 2015.

For males, suicide mortality demonstrated statistically significant declines in 25 countries (largest decrease in Kyrgyzstan: $-69 \%, 95 \%$ CI $-82 \%$ to $-44 \%$ ) but increases in Ecuador and Republic of Korea (largest increase in Ecuador: 226\%, 95\% CI 97\% to 438\%) between 2000 and 2015 (table 3). A 24-fold and 37 -fold suicide mortality rate gap, respectively, existed across the 58 countries in 2000 (5.3 per 100000 people in South Africa and 132.4 per 100000 people in Serbia) and in 2015 (2.8 per 100000 people in South Africa and 106.0 per 100000 people
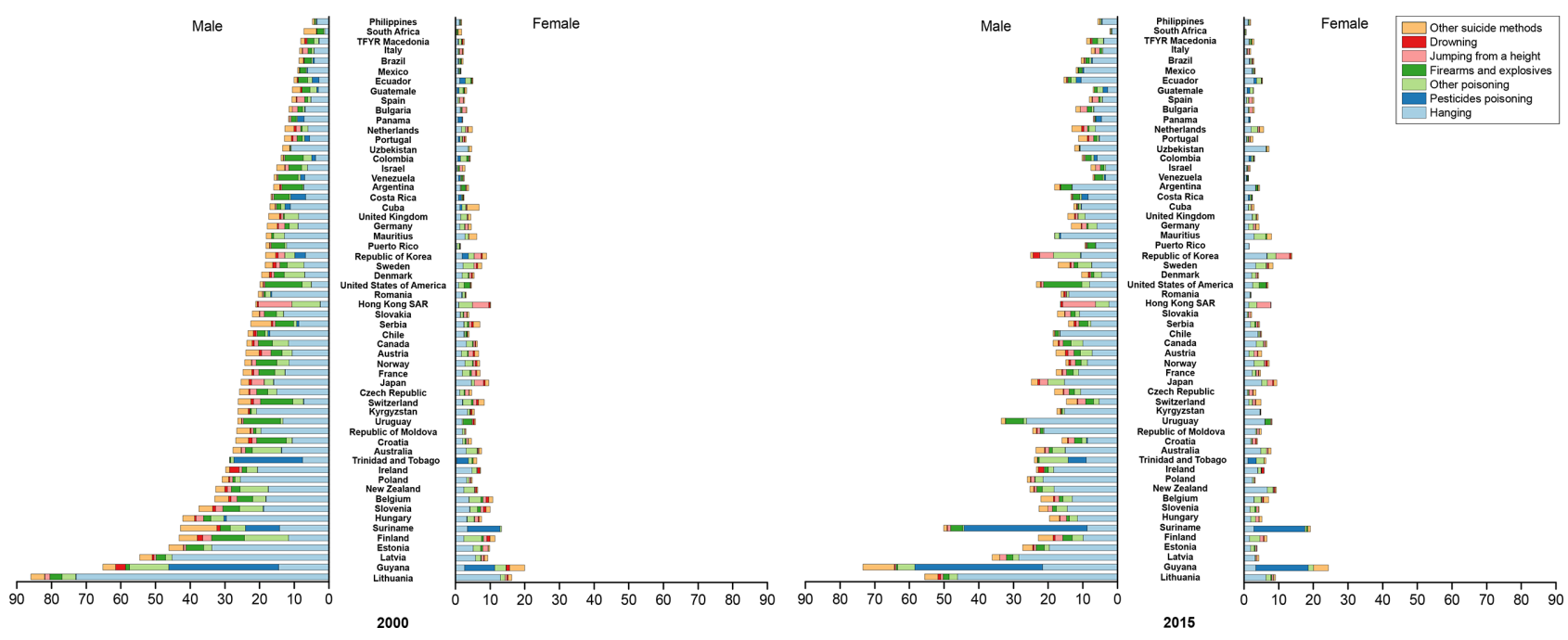

Figure 1 Variation of method-specific suicide mortality rates among persons aged 15-44 years in 2000 and 2015 (/100 000 people) notes: mortality rates were age adjusted using the new WHO world standard population (who millennium). 
Table 2 Age-standardised mortality (/100 000 persons) and percent change in mortality between 2000 and 2015 among persons aged 45-64 years

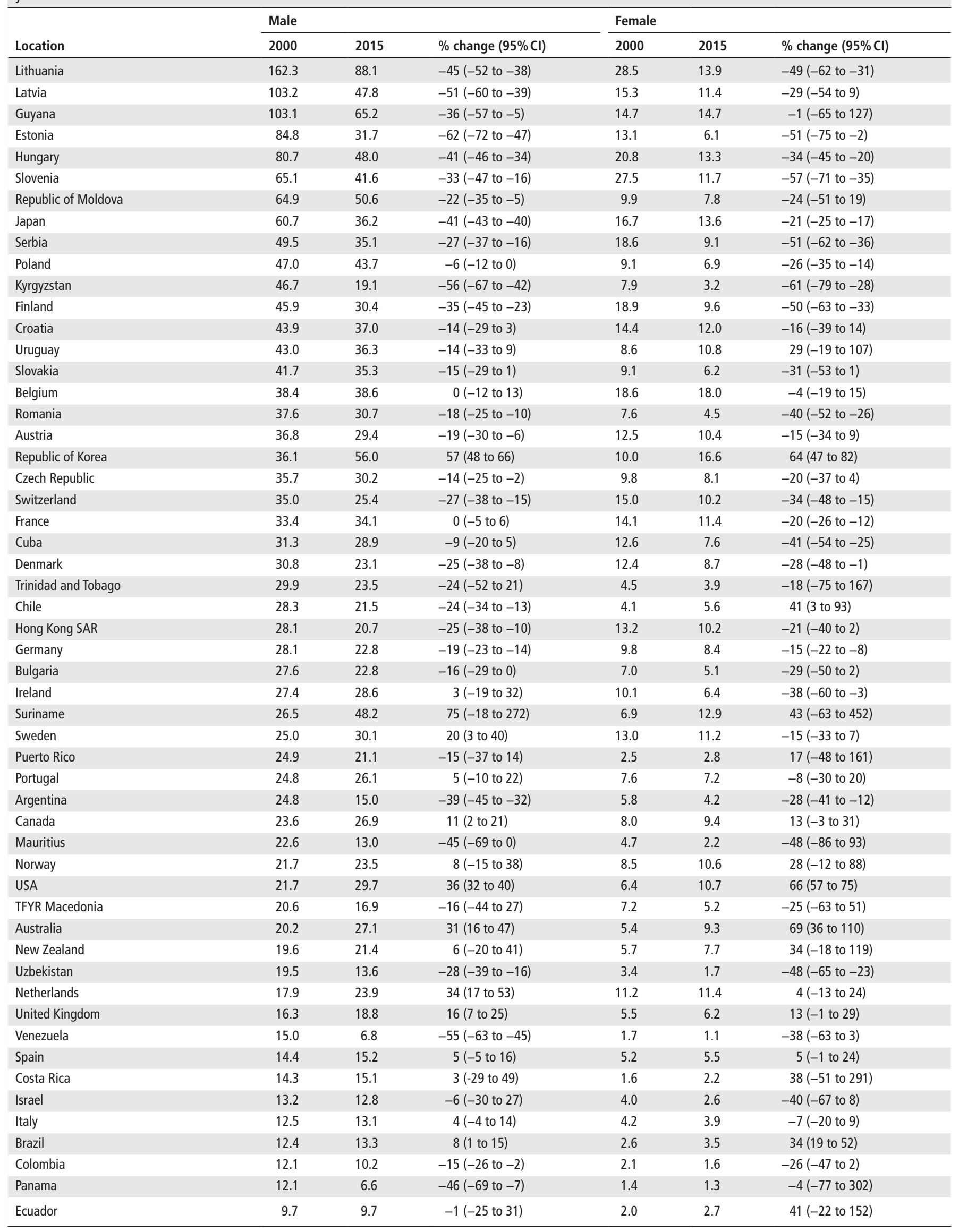


Table 2 Continued

\begin{tabular}{|c|c|c|c|c|c|c|}
\hline \multirow[b]{2}{*}{ Location } & \multicolumn{3}{|l|}{ Male } & \multicolumn{3}{|c|}{ Female } \\
\hline & 2000 & 2015 & $\%$ change $(95 \% \mathrm{Cl})$ & 2000 & 2015 & $\%$ change $(95 \% \mathrm{Cl})$ \\
\hline Guatemala & 9.2 & 6.3 & $-31(-53$ to 0$)$ & 0.9 & 0.7 & -27 (-76 to 117$)$ \\
\hline Mexico & 8.1 & 9.7 & 20 (8 to 33 ) & 1.1 & 1.6 & 37 (5 to 80$)$ \\
\hline South Africa & 6.5 & 1.6 & $-76(-82$ to -68$)$ & 0.8 & 0.5 & -42 (-67 to 1$)$ \\
\hline Philippines & 5.3 & 4.9 & -5 (-19 to 12$)$ & 1.3 & 1.2 & -3 ( -29 to 34$)$ \\
\hline
\end{tabular}

Mortality rates were age adjusted using the new WHO world standard population (WHO millennium).

in Republic of Korea) (table 3). Between 2000 and 2015, the most prevalent suicide method changed from firearms and explosives to hanging in five countries (Uruguay, Argentina, Canada, Colombia and Suriname) and from hanging to firearms and explosives in Finland (figure 3, online supplementary tables S5 and S6). The most common suicide method was hanging in 50 countries; firearms and explosives in 5 countries; and other poisoning, pesticide poisoning and jumping from a height in 1 country each in 2015 (figure 3, online supplementary table S6).

For females, suicide mortality decreased at a statistically significant rate in 26 countries (largest in Kyrgyzstan: -74\%, 95\% CI $-90 \%$ to $-32 \%$ ) and increased in Republic of Korea and USA (greatest in Republic of Korea: 46\%, 95\% CI 32\%, $61 \%$ ) between 2000 and 2015 (table 3). Female suicide mortality ranged greatly across the 58 countries in both $2000(0.8$ per 100000 people in South Africa and 48.2 per 100000 people in Serbia) and in 2015 (0.3 per 100000 people in South Africa and 32.2 per 100000 people in Republic of Korea (table 3). Between 2000 and 2015, the most prevalent suicide method changed from other poisoning to hanging in Costa Rica; from pesticide poisoning to hanging in Republic of Korea and Ecuador; from pesticide poisoning to other poisoning in Trinidad and Tobago; from hanging to other poisoning in Finland, Norway and Netherlands; and from firearms and explosives to other poisoning in the USA (figure 3, online supplementary tables S5 and S6). In 2015, the most frequent suicide method was hanging in 42 countries, other poisoning in 13 countries, pesticide poisoning in 2 countries, and jumping from a height in 1 country (figure 3 , online supplementary table S6).

\section{DISCUSSION \\ Key findings}

Using the WHO mortality database, this study updates previously published research ${ }^{10}$ with more recent sex-specific, agespecific and country-specific suicide rates, as well as reporting new patterns of suicide mortality between 2000 and 2015 in 58 countries with robust subgroup rates. Suicide mortality declined substantially for both sexes and all included age groups in most but not all of the 58 countries between 2000 and 2015. Males consistently had much higher suicide mortality rates than females in all countries. Hanging replaced non-pesticide poisoning as the most common suicide method in the majority of 58 countries between 2000 and 2015. Sex-specific suicide mortality methods varied across the 58 countries for all three age groups. The spectrum of suicide methods generally remained stable in most countries but changed notably in a few countries between 2000 and 2015 .

\section{Interpretation of findings}

The decrease in suicide mortality in most countries may reflect the effects of global and national prevention efforts. ${ }^{2}$ In the past few decades, WHO has published several documents to advocate global action to prevent suicide. These include efforts to inspire governments and policy-makers to establish or revise national suicide prevention strategies ${ }^{24}$ and to advocate for effective evidence-based interventions such as promoting responsible media reporting ${ }^{25}$ and improving risk intervention through crisis helplines. A few nations, such as Switzerland and Australia, now
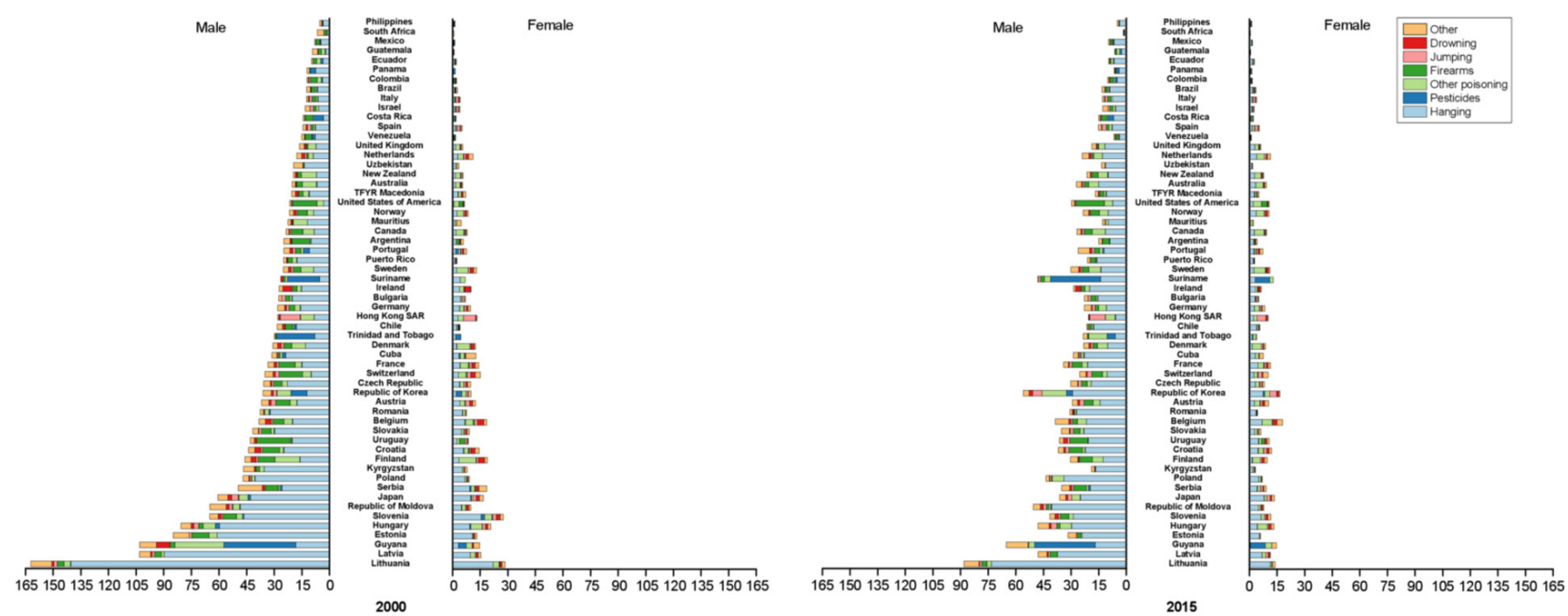

Figure 2 Variation of method-specific suicide mortality rates among persons aged 45-64 years in 2000 and 2015 (/100 000 people) notes: mortality rates were age adjusted using the new who world standard population (who millennium). 
Table 3 Age-standardised mortality (/100 000 persons) and per cent change in mortality between 2000 and 2015 among persons aged 65 years and older

\begin{tabular}{|c|c|c|c|c|c|c|}
\hline \multirow[b]{2}{*}{ Location } & \multicolumn{3}{|l|}{ Male } & \multicolumn{3}{|c|}{ Female } \\
\hline & 2000 & 2015 & $\%$ change $(95 \% \mathrm{Cl})$ & 2000 & 2015 & $\%$ change $(95 \% \mathrm{Cl})$ \\
\hline Serbia & 132.4 & 66.8 & $-45(-52$ to -37$)$ & 48.2 & 20.7 & $-54(-62$ to -44$)$ \\
\hline Hungary & 102.3 & 64.6 & $-34(-41$ to -25$)$ & 36.9 & 17.3 & $-51(-58$ to -41$)$ \\
\hline Latvia & 99.8 & 51.8 & $-44(-59$ to -24$)$ & 25.6 & 13.8 & $-45(-63$ to -17$)$ \\
\hline Lithuania & 95.6 & 86.2 & $-12(-29$ to 10$)$ & 26.6 & 18.0 & $-32(-51$ to -6$)$ \\
\hline Austria & 77.8 & 52.6 & $-28(-38$ to -17$)$ & 16.8 & 11.7 & $-29(-45$ to -9$)$ \\
\hline Cuba & 69.0 & 59.9 & $-12(-24$ to 0$)$ & 18.6 & 13.1 & $-27(-44$ to -6$)$ \\
\hline Estonia & 62.6 & 55.0 & -2 ( -36 to 50$)$ & 26.8 & 7.0 & $-70(-84$ to -43$)$ \\
\hline Republic of Korea & 59.5 & 106.0 & 93 (78 to 110$)$ & 24.4 & 32.2 & 46 (32 to 61$)$ \\
\hline Switzerland & 59.0 & 37.6 & $-36(-46$ to -24$)$ & 20.0 & 10.3 & $-52(-63$ to -37$)$ \\
\hline Portugal & 54.6 & 47.6 & $-6(-18$ to 8$)$ & 10.8 & 12.3 & $18(-8$ to 50$)$ \\
\hline Belgium & 52.1 & 34.5 & $-30(-39$ to -18$)$ & 15.3 & 12.6 & $-16(-33$ to 4$)$ \\
\hline Bulgaria & 51.7 & 39.7 & -15 (-28 to 2$)$ & 15.6 & 10.0 & $-27(-45$ to -4$)$ \\
\hline TFYR Macedonia & 51.7 & 31.8 & $-30(-56$ to 12$)$ & 15.1 & 9.7 & -34 (-68 to 37$)$ \\
\hline Guyana & 51.6 & 71.5 & 23 (-50 to 200$)$ & 10.8 & 7.1 & -19 (-89 to 475$)$ \\
\hline Japan & 48.6 & 34.9 & $-27(-30$ to -24$)$ & 24.8 & 15.2 & $-41(-44$ to -38$)$ \\
\hline Germany & 47.8 & 34.9 & $-17(-22$ to -13$)$ & 14.5 & 10.8 & $-27(-32$ to -20$)$ \\
\hline Kyrgyzstan & 45.5 & 14.7 & $-69(-82$ to -44$)$ & 12.7 & 3.3 & $-74(-90$ to -32$)$ \\
\hline Slovakia & 42.3 & 39.9 & $-7(-29$ to 23$)$ & 8.8 & 4.2 & $-52(-73$ to -16$)$ \\
\hline Denmark & 41.6 & 22.7 & $-47(-59$ to -33$)$ & 13.5 & 10.3 & $-29(-49$ to 0$)$ \\
\hline Hong Kong SAR & 41.1 & 32.7 & -16 (-33 to 5$)$ & 23.6 & 17.1 & $-26(-44$ to -3$)$ \\
\hline Venezuela & 31.9 & 10.5 & $-67(-75$ to -57$)$ & 4.3 & 1.5 & $-64(-80$ to -32$)$ \\
\hline Romania & 31.1 & 30.5 & $-1(-12$ to 15$)$ & 8.7 & 6.7 & $-22(-38$ to -2$)$ \\
\hline USA & 30.1 & 30.8 & 0 (-4 to 4$)$ & 4.1 & 5.4 & 28 (18 to 40$)$ \\
\hline Mauritius & 27.8 & 9.3 & -70 (-91 to 0$)$ & 8.0 & 2.7 & $-60(-93$ to 141$)$ \\
\hline Italy & 25.0 & 17.5 & $-26(-32$ to -19$)$ & 6.0 & 4.0 & $-36(-45$ to -26$)$ \\
\hline Australia & 23.4 & 21.6 & -5 (-20 to 11$)$ & 5.6 & 5.6 & 1 ( -25 to 35$)$ \\
\hline Puerto Rico & 23.0 & 26.0 & 16 (-22 to 72$)$ & 1.8 & 0.8 & -38 (-86 to 178$)$ \\
\hline Norway & 22.8 & 18.9 & $-16(-40$ to 18$)$ & 7.0 & 9.8 & 52 (-7 to 148$)$ \\
\hline Israel & 21.3 & 12.6 & $-43(-60$ to -17$)$ & 8.1 & 4.9 & -41 (-65 to 1) \\
\hline New Zealand & 20.8 & 13.7 & -33 (-56 to 3$)$ & 2.1 & 2.8 & 28 ( -53 to 247$)$ \\
\hline Panama & 20.8 & 9.0 & $-56(-79$ to -10$)$ & 1.2 & 1.0 & $-9(-90$ to 1103$)$ \\
\hline Netherlands & 20.3 & 20.1 & -1 (-16 to 22$)$ & 8.5 & 8.2 & -7 ( -28 to 20$)$ \\
\hline Canada & 19.5 & 17.1 & -12 (-23 to 2$)$ & 4.3 & 4.0 & 0 (-24 to 31$)$ \\
\hline Colombia & 19.2 & 17.3 & $-9(-25$ to 11$)$ & 1.1 & 1.6 & 46 ( -25 to 184$)$ \\
\hline Suriname & 19.1 & 58.8 & $123(-40$ to 723$)$ & 12.4 & 12.8 & $4(-83$ to 522$)$ \\
\hline Ireland & 18.8 & 15.2 & -17 (-48 to 30$)$ & 4.5 & 2.4 & $-38(-76$ to 60$)$ \\
\hline Costa Rica & 18.8 & 11.7 & $-38(-66$ to 15$)$ & 4.0 & 1.2 & $-68(-92$ to 33$)$ \\
\hline Brazil & 18.4 & 17.6 & $0(-9$ to 10$)$ & 3.1 & 3.1 & 1 (-17 to 22$)$ \\
\hline Guatemala & 16.7 & 5.5 & $-63(-79$ to -36$)$ & 1.6 & 1.3 & -14 (-76 to 204$)$ \\
\hline Uzbekistan & 11.8 & 9.3 & -25 ( -49 to 9$)$ & 3.3 & 2.4 & -30 (-62 to 28$)$ \\
\hline UK & 11.5 & 11.7 & $2(-10$ to 15$)$ & 3.8 & 3.6 & -7 ( -23 to 12$)$ \\
\hline
\end{tabular}


Table 3 Continued

\begin{tabular}{|c|c|c|c|c|c|c|}
\hline \multirow[b]{2}{*}{ Location } & \multicolumn{3}{|l|}{ Male } & \multicolumn{3}{|c|}{ Female } \\
\hline & 2000 & 2015 & $\%$ change $(95 \% \mathrm{Cl})$ & 2000 & 2015 & $\%$ change $(95 \% \mathrm{Cl}$ \\
\hline Mexico & 11.5 & 10.9 & -4 (-18 to 12$)$ & 1.0 & 0.8 & -23 ( -53 to 25$)$ \\
\hline Philippines & 8.3 & 8.1 & -5 (-28 to 23$)$ & 2.2 & 1.2 & $-46(-67$ to -9$)$ \\
\hline Ecuador & 6.1 & 19.7 & 226 (97 to 438$)$ & 1.0 & 2.1 & 132 (-35 to 721$)$ \\
\hline South Africa & 5.3 & 2.8 & $-46(-67$ to -12$)$ & 0.8 & 0.3 & $-62(-87$ to 11$)$ \\
\hline
\end{tabular}

Mortality rates were age adjusted using the new WHO world standard population (WHO millennium).

include restriction of suicide means in their national suicide prevention strategies and programmes. ${ }^{926}$ In addition, improved availability of mental health and welfare services may have contributed to global reductions in suicide mortality. ${ }^{27} 28$

During the study period, a number of countries witnessed significant changes in the suicide method used. ${ }^{14} 1529$ These changes are likely due to trends in sociocultural acceptability of suicide and mental health, plus access to specific suicide methods. ${ }^{6} 30$ The rising rate of suicide by hanging in many countries, for example, might be attributed to prevention efforts focused on limiting access to firearms. ${ }^{14}$ In addition, unlike suicide by other methods, suicide by hanging is less likely to be misclassified as unintentional or undetermined death. ${ }^{31}$ The decrease of suicide by other poisoning (typically drug poisoning) in some countries has been linked to the implementation of careful and appropriate medication prescribing and dosing, such as restricting size of analgesic packs in the $\mathrm{UK}^{32}$ and withdrawal of co-proxamol throughout Europe. ${ }^{33}$ Improved firearm legislation and restriction of firearm availability may partially explain the drops in suicide mortality by firearm in New Zealand, ${ }^{34}$ Australia $^{35}$ and in Switzerland. ${ }^{36}$ Finally, the adoption of strengthened pesticide regulations and restrictions may have led to substantial decreases in suicide by pesticide in Republic of Korea, despite an increase in overall suicide mortality in this nation. ${ }^{37}$

Notably, some countries witnessed significant increases in suicide mortality between 2000 and 2015 (eg, the Republic of Korea and the USA). Published studies suggest the increases may be explained by various factors, including economic recession, ${ }^{38}{ }^{39}$ widening income inequalities, ${ }^{40}$ increased unemployment $^{41}$ and ease access to highly lethal methods like firearms.
Birth cohort effects may also contribute, given cohort population exposures to the Great Depression and the Korean War. ${ }^{42}$

In accordance with previous reports, ${ }^{43}$ this study reported comparatively higher suicide mortality in males compared with females in all 58 included countries. Male-female disparities are interpreted as sex differences in help-seeking behaviour to treat mental health crises and suicidality, ${ }^{44}$ ownership of guns, ${ }^{45}$ unemployment rates, ${ }^{46}$ life roles and alcohol consumption and dependence. ${ }^{44}$ Males also are more likely to choose highly lethal suicide methods compared with females. ${ }^{47}$

Also in concordance with previous reports, ${ }^{2} 10$ we found significant variation in suicide rates across countries. These variations can be interpreted as the combined effects of socioeconomic development, religion, laws and policies, availability of lethal methods, suicide prevention efforts, mental health treatment availability and cultural acceptance of it, and prehospital and hospital treatment. ${ }^{46}$

\section{Policy implications}

Our findings offer societal benefits through two major policy implications. First, the recent decrease of suicide mortality in most of the 58 included countries highlights the apparent success of global and national suicide prevention efforts. The progress demonstrates the role of evidence-based public health interventions and suggests that the SDGs target for suicide prevention may be achievable if the recommended interventions are fully implemented. Second, our results underscore the urgency and importance of efforts to reduce disparities in suicide mortality and mortality change. The global suicide prevention community,
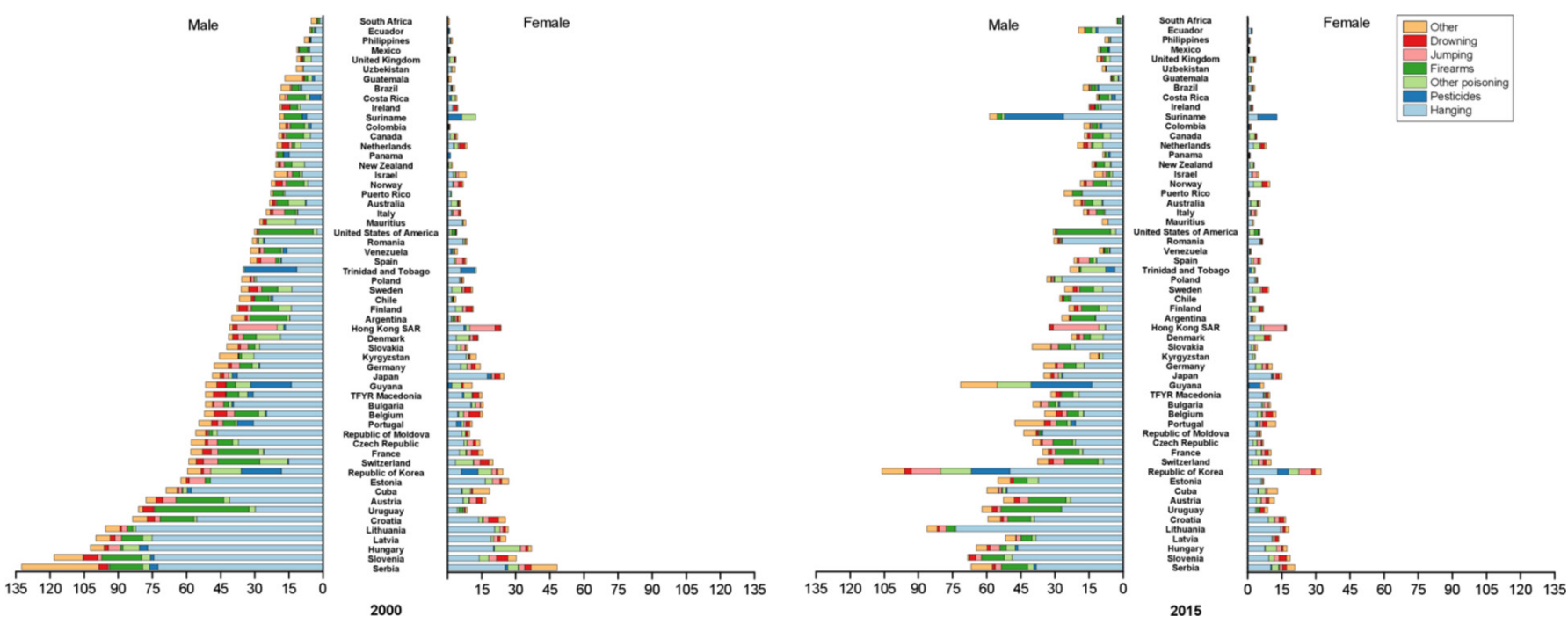

Figure 3 Variation of method-specific suicide mortality rates among persons aged 65 years and older in 2000 and 2015 (/100 000 people) notes: mortality rates were age-adjusted using the new who world standard population (who millennium). 
and especially the governments of countries with high suicide mortality rates and those with small suicide mortality reductions (or mortality increases) between 2000 and 2015, should collaborate to identify reasons for the disparities and develop solutions to reduce them. The reduction of disparities between countries, and subsequent reduction of suicide rates in high-risk countries, will be a critical strategy to attain the global SDGs suicide prevention target. From a research perspective, continued work to generate evidence-based strategies for global and national suicide policy interventions should be pursued.

\section{Study limitations}

Our analyses were limited by three factors. First, we were limited by data availability. Many countries were excluded because they did not report data to the WHO mortality database, including China, India and Russia. We also excluded countries with small annual suicide deaths in order to obtain robust subgroup suicide mortality rates by sex, age group and suicide method. Complete analyses could be made if the GBD study group extended their database to offer detailed groups of fatalities by suicide method rather than estimating only two groups (self-harm by firearm and self-harm by other specified means). ${ }^{1}$ Second, due to lack of data concerning relevant risk factors such as previous suicide attempts, mental health disorders, substance use disorders and inappropriate media reporting, we cannot explain the causality of suicide rate changes and mortality differences by sex, age, suicide method and country. Last, given the social taboo of suicide in almost all cultures, data on suicide rates suffer from challenges in data quality, including underreporting and misclassification. Such effects likely impact our results, especially for those countries with poor-quality suicide mortality data and those with particularly strong sociocultural biases concerning suicidality.

\section{CONCLUSIONS}

Substantial suicide mortality decreases occurred between 2000 and 2015 in 37 of the 58 countries (64\%) included in this study. The suicide spectrum by method experienced substantial changes in several countries, likely reflecting combined influences of changes in population sociodemographic characteristics and organised suicide prevention efforts. Results amplify calls for further research to explore specific drivers of the observed changes, including especially the increases in suicide rates we

\section{What is already known on this subject}

- Suicide is a serious global public health problem.

- Suicide method varies substantially by sex and age group and across countries.

- Recent suicide mortality by method has not been examined across countries.

\section{What this study adds}

- Between 2000 and 2015, suicide mortality decreased in 37 of the included 58 countries but increased in 8 countries.

- The suicide spectrum by method experienced substantial changes in several countries between 2000 and 2015.

- Hanging is the most prevalent suicide method in most included countries. witnessed in eight countries, and to understand disparities in suicide rates across countries. Results also amplify urgent need to continue global suicide prevention efforts.

Contributors $\mathrm{GQH}$ conceived of the project. $\mathrm{GQH}$ and $\mathrm{YW}$ designed the study. YW, YH, PSN and PXC analyzed and interpreted the data. YW and GQH drafted the manuscript. DCS reviewed and revised the manuscript critically for important content. All authors approved the final version and take responsibility for the integrity of the work.

Funding The authors have not declared a specific grant for this research from any funding agency in the public, commercial or not-for-profit sectors.

Competing interests None declared.

Patient consent for publication Not required.

Provenance and peer review Not commissioned; externally peer reviewed.

Data availability statement Data are available in a public, open access repository. As for the link to the data availability, all data of this paper are freely accessible in the WHO Mortality dataset (http://apps.who.int/healthinfo/statistics/ mortality/causeofdeath_query/).

Open access This is an open access article distributed in accordance with the Creative Commons Attribution Non Commercial (CC BY-NC 4.0) license, which permits others to distribute, remix, adapt, build upon this work non-commercially, and license their derivative works on different terms, provided the original work is properly cited, appropriate credit is given, any changes made indicated, and the use is non-commercial. See: http://creativecommons.org/licenses/by-nc/4.0/.

\section{ORCID iDs}

David C Schwebel http://orcid.org/0000-0002-2141-8970

Guoqing Hu http://orcid.org/0000-0002-5002-8015

\section{REFERENCES}

1 GBD 2017 Causes of Death Collaborators. Global, regional, and national agesex-specific mortality for 282 causes of death in 195 countries and territories, 1980-2017: a systematic analysis for the global burden of disease study 2017. Lancet 2018;392:1736-88.

2 WHO. Preventing suicide a global imperative. Geneva, Switzerland: World Health organization, 2014. Available: https://www.who.int/mental_health/suicide-prevention/ world_report_2014/en/ [Accessed 15 Sep 2018].

3 United Nations. Transforming our world: the 2030 agenda for sustainable development, 2015. Available: https://sustainabledevelopment.un.org/content/ documents/21252030\%20Agenda\%20for\%20Sustainable\%20Development\% 20web.pdf [Accessed 15 Sep 2018].

4 Mann JJ, Apter A, Bertolote J, et al. Suicide prevention strategies: a systematic review. JAMA 2005:294:2064-74.

5 Zalsman G, Hawton K, Wasserman D, et al. Suicide prevention strategies revisited: 10-year systematic review. Lancet Psychiatry 2016;3:646-59.

6 Yip PSF, Caine E, Yousuf $S$, et al. Means restriction for suicide prevention. Lancet 2012;379:2393-9.

7 U.S. Office of the Surgeon General, National Action Alliance for Suicide Prevention. 2012 national strategy for suicide prevention goals and objectives for action. Washington, DC: HHS, 2012.

8 WHO. Comprehensive mental health action plan 2013-2020 in: organization wh, editor. Geneva, Switzerland: the WHO Document Production Services, 2013.

9 Council of Australian Governments Health Council. The fifth national mental health and suicide prevention plan Canberra. Commonwealth of Australia, 2018.

10 Ajdacic-Gross V, Weiss MG, Ring M, et al. Methods of suicide: international suicide patterns derived from the who mortality database. Bull World Health Organ 2008:86:726-32.

11 Naghavi M, Marczak LB, Kutz M, et al. Global mortality from firearms, 1990-2016. JAMA 2018;320:792-814

12 Chang S-S, Chen Y-Y, Yip PSF, et al. Regional changes in charcoal-burning suicide rates in East/Southeast Asia from 1995 to 2011: a time trend analysis. PLoS Med 2014;11:e1001622.

13 Sullivan EM, Annest JL, Simon TR, et al. Suicide trends among persons aged 10-24 years--United States, 1994-2012. MMWR Morb Mortal Wkly Rep 2015;64:201-5.

14 Puzo Q, Qin P, Mehlum L. Long-Term trends of suicide by choice of method in Norway: a joinpoint regression analysis of data from 1969 to 2012. BMC Public Health 2016;16:255.

15 Dhungel B, Sugai MK, Gilmour S. Trends in suicide mortality by method from 1979 to 2016 in Japan. Int J Environ Res Public Health 2019;16:1794.

16 WHO. Mortality Database: Cause of Death Query Online [Internet], 2018. Available: http://apps.who.int/healthinfo/statistics/mortality/causeofdeath_query/ [Accessed 15 Sep 2018].

17 WHO. Who methods and data sources for global causes of death, 2000-2016. Geneva, Switzerland: World Health Organization, 2018. 
18 Mathers CD, Lopez AD, Murray CJL, et al. The burden of disease and mortality by condition: data, methods, and results for 2001. global burden of disease and risk factors. New York: Oxford University Press, 2006: 45-240.

19 Crepeau-Hobson F. The psychological autopsy and determination of child suicides: a survey of medical examiners. Arch Suicide Res 2010;14:24-34.

20 Yoshioka E, Hanley SJ, Kawanishi Y, et al. Time trends in method-specific suicide rates in Japan, 1990-2011. Epidemiol Psychiatr Sci 2016;25:58-68.

21 Kõlves K, McDonough M, Crompton D, et al. Choice of a suicide method: trends and characteristics. Psychiatry Res 2018;260:67-74.

22 Ahmad OB, Boschi-Pinto C, Lopez AD, et al. Age standardization of rates: a new who standard. Geneva, Switzerland: World Health organization, 2001. Available: http:// www.who.int/healthinfo/paper31.pdf [Accessed 15 Sep 2018].

23 Wang L, Wu Y, Yin P, et al. Poisoning deaths in China, 2006-2016. Bull World Health Organ 2018;96:314-26.

24 WHO. National suicide prevention strategies: progress, examples and indicators. Geneva: World Health organization, 2018. Available: https://www.who.int/mental_ health/suicide-prevention/national_strategies_2019/en/ [Accessed 15 Sep 2018].

25 WHO. Preventing suicide: a resource for media professionals. Geneva: World Health organization, 2008. Available: http://www.who.int/mental_health/prevention/suicide/ resource_media.pdf [Accessed 15 Sep 2018].

26 Federal office of public health FOPH. Suicide prevention in Switzerland starting point, need for action and action plan. Berne, 2018.

27 Snowdon J, Chen Y-Y, Zhong B, et al. A longitudinal comparison of age patterns and rates of suicide in Hong Kong, Taiwan and Japan and two Western countries. Asian J Psychiatr 2018;31:15-20.

28 While D, Bickley $\mathrm{H}$, Roscoe A, et al. Implementation of mental health service recommendations in England and Wales and suicide rates, 1997-2006: a crosssectional and before-and-after observational study. Lancet 2012;379:1005-12.

29 Baker SP, Hu G, Wilcox HC, et al. Increase in suicide by hanging/suffocation in the U.S., 2000-2010. Am J Prev Med 2013;44:146-9.

30 Thomas KH, Beech E, Gunnell D. Changes in commonly used methods of suicide in England and Wales from 1901-1907 to 2001-2007. J Affect Disord 2013;144:235-9.

31 Morovatdar N, Moradi-Lakeh M, Malakouti SK, et al. Most common methods of suicide in eastern Mediterranean region of who: a systematic review and metaanalysis. Arch Suicide Res 2013;17:335-44.

32 Hawton K, Simkin S, Deeks J, et al. Uk legislation on analgesic packs: before and after study of long term effect on poisonings. BMJ 2004;329:1076.
33 Hawton K, Bergen H, Simkin S, et al. Long term effect of reduced pack sizes of paracetamol on poisoning deaths and liver transplant activity in England and Wales: interrupted time series analyses. BMJ 2013;346:f403.

34 Beautrais A, Fergusson D, Coggan C, et al. Effective strategies for suicide prevention in New Zealand: a review of the evidence. N Z Med J 2007;120:U2459.

35 Chapman S, Alpers $\mathrm{P}$, Jones M. Association between gun law reforms and intentional firearm deaths in Australia, 1979-2013. JAMA 2016;316:291-9.

36 Reisch T, Steffen T, Habenstein A, et al. Change in suicide rates in Switzerland before and after firearm restriction resulting from the 2003 "Army XXI" reform. Am J Psychiatry 2013;170:977-84.

37 Gunnell D, Knipe D, Chang S-S, et al. Prevention of suicide with regulations aimed at restricting access to highly hazardous pesticides: a systematic review of the International evidence. Lancet Glob Health 2017;5:e1026-37.

38 Reeves A, Stuckler D, McKee M, et al. Increase in state suicide rates in the USA during economic recession. Lancet 2012;380:1813-4.

39 Chang S-S, Stuckler D, Yip P, et al. Impact of 2008 global economic crisis on suicide: time trend study in 54 countries. BMJ 2013;347: $\{5239$.

40 Hiyoshi A, Kondo N, Rostila M. Increasing income-based inequality in suicide mortality among working-age women and men, Sweden, 1990-2007: is there a point of trend change? J Epidemiol Community Health 2018;72:1009-15.

41 Garcy AM, Vågerö D. Unemployment and suicide during and after a deep recession: a longitudinal study of 3.4 million Swedish men and women. Am J Public Health 2013;103:1031-8.

42 Jeon SY, Reither EN, Masters RK. A population-based analysis of increasing rates of suicide mortality in Japan and South Korea, 1985-2010. BMC Public Health 2016;16:356.

43 Ivey-Stephenson AZ, Crosby AE, Jack SPD, et al. Suicide Trends Among and Within Urbanization Levels by Sex, Race/Ethnicity, Age Group, and Mechanism of Death United States, 2001-2015. MMWR Surveill Summ 2017;66:1-16.

44 Oliver Ml, Pearson N, Coe $\mathrm{N}$, et al. Help-Seeking behaviour in men and women with common mental health problems: cross-sectional study. Br J Psychiatry 2005; 186:297-301.

45 Möller-Leimkühler AM. The gender gap in suicide and premature death or: why are men so vulnerable? Eur Arch Psychiatry Clin Neurosci 2003;253:1-8.

46 Fountoulakis KN, Chatzikosta I, Pastiadis K, et al. Relationship of suicide rates with climate and economic variables in Europe during 2000-2012. Ann Gen Psychiatry 2016;15:19.

47 Roškar S, Zorko M, Podlesek A. Suicide in Slovenia between 1997 and 2010. Crisis 2015:36:126-34 